\title{
DEGREE SEMANTICS FOR RUSSIAN VERBAL PREFIXES: THE CASE OF POD- AND DO-
}

\author{
OLGA KAGAN \\ Ben-Gurion University of the Negev
}

\section{[1] INTRODUCTION}

Verbal prefixation plays a central role in Slavic aspectual system and word formation. Although a lot of work is devoted to the semantics of verbal prefixation in Slavic, numerous questions regarding the semantic nature of the prefixes remain open.

Descriptively speaking, prefixation constitutes the most common means of perfectivization in Slavic languages. For instance, while the verb pisat' (write) is imperfective, such verbs as napisat' (write), perepisat' (rewrite) and podpisat' (sign) are all perfective. Still, as argued convincingly by Filip (2000), verbal prefixes cannot be analyzed as inflectional perfectivizing morphemes, and their semantics cannot be equated to perfectivization. Thus, a prefix can be attached to a verb that is already perfective and, as such, cannot undergo perfectivization. Further, a verb that contains a prefix may be imperfective, if it also contains an imperfectivizing suffix. Semantics of such verbs does not generally involve an application of a perfective operator, despite the presence of the prefixes. Moreover, as illustrated above, a given stem may combine with different prefixes, since, in addition to having a perfectivizing effect, such prefixes are associated with a wide range of further semantic contributions. A prefix may contribute a spatial, cumulative, diminutive, inchoative, completive or distributive interpretation, to list just a few possibilities. Given such variation, is it possible to make any generalizations regarding the semantics of verbal prefixes? Or do we have to confine ourselves to investigating the properties of each prefix in isolation?

The situation is further complicated by the fact that a prefix with a given phonological realization may be associated with multiple meanings. For instance, the Russian prefix pere- may contribute a spatial interpretation "to cross" (e.g.perejti 'cross by walking'), one of excess (perepit' 'drink too much'), an iterative meaning (perečitat' 'reread'), a distributive meaning (perestreljat' 'shoot one by one'). The different uses of a single phonological prefix are set even further apart in the context of the lexical/superlexical contrast. Lexical prefixes affect the lexical meaning of the verb; they may change its argument structure; their contribution may be idiosyncratic and not (fully) compositional, and they are compatible with 
secondary imperfectivization. In contrast, the contribution of superlexical prefixes is transparent; they do not change the lexical meaning or argument structure of the verb, but rather contribute some kind of quantificational or aspectual meaning in a purely compositional manner; further, they are typically incompatible with secondary imperfectivization (e.g. Babko-Malaya (1999); Romanova (2004); Svenonius (2004)). Importantly, the same string of sounds may correspond to a lexical prefix under one meaning and to a superlexical one under another. As a result, in the literature that concentrates on the lexical/superlexical distinction, such strings are sometimes implicitly treated as distinct prefixes ${ }^{1}$. An important theoretical question thus emerges regarding the status of such items, which are identical phonologically but not semantically. Should they be treated as a single prefix with a uniform but indeterminate meaning, and, thus, be provided a unified account? (This approach, whereby an invariant meaning of a prefix is sought, is in the spirit of Jakobson's work and has been recently applied to certain prefixes in Russian and Czech by Braginsky (2008) and Součková $(2004 a, b)$.) Or should they rather be regarded as exhibiting polysemy or homonymy? With different prefixes, different answers may be correct. Further, assuming that for some prefixes, a unified account is the right solution, can we make any generalizations as to what aspects of meaning are likely to remain stable across multiple uses and what are the likely parameters of variation?

The purpose of this paper is to contribute to the study of Slavic prefixation and to the investigation of the issues raised above. I propose an approach to verbal prefixes that is formulated within the framework of degree semantics. Under this approach, the major semantic function of a prefix is to impose a certain relation between two degrees on a scale. Prefixes differ in the type of the scale to which they apply, in the properties of the compared degrees and in the relation that holds between the degrees and the event argument contributed by the verbal stem.

Importantly, the notion of scales and degrees has received a central role in a number of recent approaches to telicity, perfectivity and perfectivization (e.g. Kennedy \& Levin (2002, 2008); Filip \& Rothstein (2006); Filip (2008); Rappaport Hovav (2008, 2009); Piñón (2008) ). For instance, Kennedy \& Levin (2002) define verbs of gradual change, which denote events that involve an increase in the degree to which their argument possesses a certain gradable property (p. 5). To illustrate, the degree achievement cool denotes an increase in the degree of coolness. Analogously, the verb of motion ascend entails a progress along a path on the part

[1] It should be emphasized, however, that a polysemy or homonymy position is not obligatory under an approach that distinguishes between lexical and superlexical uses of the same phonological prefix. Under this approach, lexical and superlexical prefixes are assumed to occupy different structural positions (superlexical prefixes attach higher than lexical ones). Therefore, such an approach is perfectly compatible with an assumption that we deal with a single prefix whose semantic contribution depends on the structural position in which it is merged. 
of its argument, and is therefore associated with an increase in the property of advancement along a path. The semantics of verbs of gradual change involves a 'degree of change argument'. This is the degree to which an argument undergoes an increase in the relevant property between the beginning point of the event and the endpoint of the event. We can think of a degree of change as the length of the interval between the point on the scale associated with the beginning of an event and the point on the same scale associated with the end of the event. The degree of change plays a crucial role in the telicity of the predicate. In particular, if the degree of change is quantized, or bounded, then an endpoint of the event can be identified, and the predicate is telic. If the degree of change is non-quantized, the predicate is atelic (Hay et al. 1999; Kennedy \& Levin 2002, 2008).

In turn, Filip (2008) and Filip \& Rothstein (2006) analyze telicity and perfectivity as maximalization on events. Perfective predicates are taken to denote sets of events that are maximal, in a given situation, relative to a particular scale (e.g. a time scale or a path scale). Turning to verbal prefixation, Filip (2008) states that certain uses of prefixes "contribute to the specification of the ordering criterion on events" and "can be assimilated to the class of scale inducing expressions". Filip points out that "[m]any prefixes historically developed from prepositions and adverbs used for the expression of directed path structures in space and time. Other meanings commonly lexicalized by prefixes are related to cardinality and measure. Directed path structures, cardinality and measurement notions are precisely the type of meaning components that have independently been uniformly represented by means of scales."

The analysis developed in this paper is in the spirit of the above-mentioned approaches in that it assigns to verbal prefixes a scalar semantics. I put forward a hypothesis that a verbal prefix imposes a relation between two degrees on a scale, one of which is a degree associated with the event denoted by the verbal predicate, and the other, the standard of comparison. A degree may be linked to an event in several different ways; for instance, this may be the degree of change argument of the event in the sense of (Kennedy \& Levin 2002). Additional possibilities will be demonstrated below. In turn, the standard of comparison can be contributed either by a linguistic expression that appears in the sentence, or by the context. The scale to which the prefix applies is typically contributed by the linguistic environment in which the prefix appears (e.g. by the verbal stem or by a direct object); in more rare cases, a lexical prefix may introduce a scale of its own. The core meaning proposed for verbal prefixes can be represented as in (1). (It will be shown in Sections [3] and [4] that the formula needs to be slightly revised in order to capture the finer distinctions imposed by certain prefixes.) This approach will be referred to below as The Scale Hypothesis. 
(1) The Scale Hypothesis (Version 1)

$$
\lambda P \lambda d \lambda x \lambda e \lambda d_{s}\left[P(d)(x)(e) \wedge d R d_{s}\right]
$$

$R$ stands for a relation between the two degrees, $d$ and $d_{s}$, the precise relation (e.g. ' $<$ ' ' '=', ' $\geq$ ') being determined by a given prefix. All the uses of a given prefix will involve the same relation between the two degrees. The different uses of a given prefix differ primarily in terms of the scale on which the two degrees are compared (e.g. a path scale, a property scale, a time scale, etc.) The intuitive contrast between the different uses, which sometimes makes them seem absolutely unrelated semantically despite the phonological identity, is to a large degree reducible to this basic distinction. With some prefixes, the uses will also differ in terms of additional properties, such as the source and the nature of $d_{s}$, the standard of comparison. Distinct prefixes may differ from one another along a whole range of parameters, which are discussed in more detail at the end of the paper, in Section [5]. Under the proposed analysis, Paillard's (1997) claim is followed according to which prefixes should be treated as relators (реляторы), which impose a relation between two items. Specifically, I propose to treat prefixes as relations between degrees.

A support of a scalar approach along the line of (1) comes from an analysis formulated by Součková (2004a) for two specific prefixes, po- and na- in Czech (the analysis is largely based on Filip's (2000) account of the prefixes po- and na-in Russian). Following Filip (2000), Součková treats these prefixes as measure functions that delimit the event. Crucially, she argues that they do so by virtue of measuring an interval on the scale that is relevant for the delimitation of the event. More precisely, they measure the degree of change of the event. (In other words, they measure a change that an event participant undergoes in some gradable property in the course of the event.) na- specifies that the degree of change reaches or exceeds a contextually provided standard; po-, on the contrary, specifies that the degree does not exceed such a standard. The different uses of the prefixes correspond to the different scales to which they apply (for instance, po- in Czech can apply to property, path and time scales). This analysis can be translated into the framework adopted in the present paper as follows:

$$
\begin{aligned}
& \llbracket p o-\rrbracket=\lambda P \lambda d \lambda x \lambda e \cdot\left[P(d)(x)(e) \wedge d \leq d_{c}\right] \\
& \llbracket n a-\rrbracket=\lambda P \lambda d \lambda x \lambda e \cdot\left[P(d)(x)(e) \wedge d \geq d_{c}\right] \\
& \text { where } d \text { is the degree of change (Kennedy \& Levin 2002) }
\end{aligned}
$$

In this paper, I argue that the analysis provided in (1) successfully applies to additional prefixes, which differ considerably from both po- and na- in terms of their properties. One goal of the paper is to propose that the analysis in (1) represents a general pattern followed by multiple prefixes which exhibit different properties and belong to different groups (rather than being an accidental prop- 
erty that happens to characterize a couple of prefixes). Importantly, I will argue that the Scale Hypothesis applies even to prefixes that are not superlexical, do not make a purely transparent contribution and do not necessarily function as event delimiters or measure functions. In what follows, the Scale Hypothesis will be discussed and argued for in four stages, briefly discussed below.

(i) In Section [2], I extend The Scale Hypothesis to the prefix pod-in Russian. This prefix is characterized by a variety of uses, mainly lexical, which are intuitively quite different from each other. I will argue that all these uses are unified by the semantic core represented in (3):

$$
\lambda P \lambda d \lambda x \lambda e \lambda d_{s} \cdot\left[P(d)(x)(e) \wedge d<d_{s}\right]^{2}
$$

The prefix consistently specifies that a certain degree on a scale associated with the event is lower than a standard of comparison. The uses of pod- differ in terms of the scale to which this prefix applies, as well as in terms of the source of the standard of comparison: with some uses, it corresponds to a contextually specified norm, while with others it is contributed by the semantics of a linguistic expression. Some lexical uses of pod- may be associated with additional meaning components.

(ii) In Section [3], the Russian prefix do- is discussed. It is proposed that the prefix identifies the point on a scale that is reached by an event participant at the endpoint of the event with a standard of comparison. It will be shown that the prefix can apply to scales with different types of dimensions, including path scales, property scales and the time scale.

(iii) In section [4], the general semantics for prefixes proposed in (1) is slightly revised, in accordance with the demands revealed in the previous sections.

(iv) In addition to capturing the semantic core that unifies different prefixes and their uses, the Scale Hypothesis allows us to identify a whole range of parameters along which prefixes are predicted to vary. These parameters are discussed in Section [5].

Only two prefixes will be discussed in this paper in detail for reasons of space. However, the choice of the prefixes is not accidental. pod-is a lexical prefix under most of its uses; it affects the lexical meaning of the verb and sometimes changes its argument structure, and its contribution is not always purely transparent. In turn, do- has properties of both lexical and superlexical prefixes. For instance, like a lexical prefix, it is compatible with secondary imperfectivization (dopisat' -

[2] I assume that $d$, the degree associated with the event, may be, and often is, existentially quantified over. 
dopisyvat' (to finish writing)), but like a superlexical prefix, it contributes an aspectual interpretation in a purely compositional way. Tatevosov (2008) captures these facts by arguing convincingly that do- belongs to a third group of intermediate prefixes. Given that the prefixes po- and na-discussed by Filip and Součková are superlexical, the discussion will allow us to conclude that the Scale Hypothesis successfully applies to prefixes belonging to all the three types - lexical, intermediate and superlexical. The prefixes pod-, do-, na- and po- differ considerably in their properties, belong to different classes and, therefore, do not form a natural class to the exclusion of the other prefixes. The fact that all these morphemes receive a scalar analysis along the line of (1) suggests that the scalar semantics is not an accidental characteristic of two or three morphemes but rather a more general property associated with Slavic verbal prefixation. Of course, future research is needed in order to determine how far The Scale Hypothesis can be extended, whether it applies to the complete set of prefixes or not, and if not, how the precise range of prefixes for which it is valid can be classified. This paper constitutes one of the first steps toward this goal and may provide a basis for future investigation. Hopefully, the direction of research developed in this paper will prove helpful in the study of additional prefixes.

\section{[2] THE PREFIX POD-}

This section is devoted to a discussion of the semantics of the prefix pod-in Russian. I will list several different uses of this prefix and then propose a semantic analysis that unifies all these uses. Roughly speaking, it will be proposed that the prefix specifies that an event, or some aspect of the event, reaches a degree on a certain scale that is lower than a standard of comparison (the latter being provided either by a PP found in the sentence or by the context). Given that the prefix is derived from the preposition pod 'under', 'below', the semantics of the prefix under the proposed analysis can be conceived of as metaphoric. The prefix specifies that the event in question reaches a degree on a scale that is located below another degree. In this sense, the analysis conforms to a generalization made by Janda $(1988,328)$ according to which a prefix usually has a spatial submeaning, with the other uses corresponding to metaphorical extensions of this submeaning. The different uses of the prefix will be argued to differ in terms of the dimension of the scale to which it applies, and in the nature of the standard of comparison. What kind of scale is involved largely depends on the properties of the predicate to which the prefix attaches.

Before we proceed to a more detailed investigation of the prefix, one complication should be mentioned. Under most uses of pod- to be discussed below it clearly functions as a lexical prefix, which affects the lexical meaning of the verb and, sometimes, changes its argument structure. As is well-known, the contribution of a lexical prefix is not always purely compositional, can be idiosyncratic, 
and may even give rise to idiomatic readings. Therefore, the meaning of some verbs that contain pod-cannot be predicted in a purely compositional manner on the basis of the (uniform) semantics of the prefix and the denotation of the stem. We should allow for certain lexical uses of the prefix in combination with certain verbs (i) to introduce idiosyncratic meaning components in addition to the uniform contribution of the prefix, and even (ii) to create idiomatic or near-idiomatic meanings. Despite these complications, degree semantics makes it possible to define a meaning component that unifies the different uses of pod-, as long as the semantics of the resulting predicate is AT LEAST PARTLY compositional (which is typically the case). The discussion of the prefix pod-is thus important for at least two reasons. First, it demonstrates how what looks like different and unrelated uses of a given prefix can be unified under a scalar analysis. Second, it shows that a scalar analysis can be applied to a lexical prefix, and not only to a superlexical one. This way, the discussion of pod-renders considerable support to the Scale Hypothesis.

This section is organized as follows. In Section [2.1], four uses of pod- are introduced on a descriptive level. In Section [2.2], I propose a formal analysis of the prefix and show how it applies to the four uses. Section [2.3] extends the discussion to an additional, fifth use of pod-. It is shown that the meaning component defined in Section [2.2] characterizes this use as well ${ }^{3}$. Section [2.4] formulates generalizations regarding the relation between the meaning of pod-and the environment in which it appears. In Section [2.6], I discuss several uses of the morpheme pod that does not function as a verbal prefix. It is shown that these uses render further support to the scalar nature of pod. Finally, Section [2.7] concludes the discussion.

\section{[2.1] The Prefix pod-: A List of Uses}

This section contains a pre-theoretical discussion of four different uses of pod-.

Vertical pod-

I begin with the use of pod- that is especially strongly related to the semantic meaning of the preposition pod (under). This use of pod-is referred to by Plungyan (2001) as nižnjaja okrestnost' (lower boundary). The precise effect of the attachment of the prefix is in part idiosyncratic, but the resulting predicates can be

[3] It should be noted that the goal of this section is not to provide an exhaustive list that would cover all the sub-uses of pod-and all the individual verbs containing this prefix. The range of such uses is quite wide, as some of them only contain very small groups of verbs; further, some verbs are characterized by especially low compositionality and by idiomatic components. My goal is rather to describe and analyze several major uses which cover a wide range of verbs that contain the prefix pod-and, by considering these uses, to demonstrate the relevance of scale structure for the analysis of the prefix. The general principle developed in the paper can be further applied to analyze additional instances of pod- even if they happen not to be listed in this paper. 
roughly divided into two types. Verbs of the first type denote events whereby an object $x$ undergoes motion, with the result of $x$ being located under an object $y$. Compositionality is to a high degree observed with verbs of placement. Such verbs, in combination with pod-, mean roughly "to put $x$ under $y$ ", with additional meaning components contributed by the lexical semantics of the root. This kind of interpretation is exhibited by such verbs as podložit' (pod-lay/put down) 'to lay $x$ under $y$ ', podstavit' (pod-put (in a vertical position)) 'to place $x$ under $y$ ', podstelit' (pod-lay/spread) 'to lay $x$ under $y$ '. The use of such verbs is exemplified in (4):
a. podložit' podušku (pod golovu)
pod-lay pillow under head
'to put a pillow (under one's head)'
b. podstavit' skameječku pod nogi
pod-put footstool under legs
'to put a footstool/a small bench under one's legs.'

Podpisat' (pod-write) is a verb whose meaning is not compositionally derived, but in which the 'under' meaning of pod- can be still made out. This verb means 'to sign'. Signing involves writing, and in the prototypical case, a signature is placed BELOW some picture / text etc. Of course, sign is not identical to write below; still, it is non-surprising that the prefix pod-is used to derive a verb with this meaning.

The second type consists of verbs in which pod- introduces the meaning of moving upward, such as podnjat ' 'lift' (the stem is a bound morpheme which cannot function as an independent word), podprygnut' (pod-jump (once)) 'jump up', and podbrosit' (pod-throw) 'throw up'. Although, perhaps surprisingly, the motion is upward, rather than downward, we can still detect the original meaning of 'under': the point in space at which the motion begins is located at the lower end of the vertical path traversed by the object. Roughly, the source is located UNDER the goal.

pod- of Approaching

pod- of approaching, which corresponds to prilegajuščaja okrestnost' (adjacent vicinity) in Plungyan's terminology, is similar to vertical pod- in that it, too, relates to the path traversed by an event participant. However, its contribution is not associated with vertical configuration. This use is found primarily with determinate (uni-directional) verbs of manner of motion, and the semantic contribution of the prefix can be intuitively described as to approach (in the manner of motion specified by the verb). This use is exemplified by podojti (pod- + idti (walk), approach by walking), podbežat' (pod- + bežat' (run), approach by running), podletet' (pod- +

[4] Note that podstavit' can be used even if one's legs are not located on/above the footstool immediately after the putting event. The verb can be used as soon as the speaker intends for someone to put his or her legs on the object in the near future. In this case, the purpose of the subject is sufficient. 
letet' (fly), approach by flying). It is also found with verbs belonging to other classes, e.g. the transitive verb pododvinut' (pod- $+d v i n u t$ ' (move), to move an object $x$ close to $y$ ). The object that is approached is typically specified by a PP headed by the preposition $k$ (towards) (alternatively, it can be specified by the context). According to (5), Masha reached (by walking) a location that is close to the store (the result state is one of her being near the store.)
Maša podošla $\mathrm{k}$ magazinu.
Masha pod-walked toward store
'Masha approached the store.'

pod- of Limited Change

Degree achievements denote an event of change whereby an event participant comes to be characterized by a gradable property to a certain degree (e.g. melt, shorten, grow). The change of state is from having the property to a degree $\mathrm{d}$ to having it to a higher degree d' (see Hay et al. (1999); Kennedy \& Levin (2002, 2008); Rothstein (2008), and references therein). (For instance, a growing event is an event whereby a participant undergoes a change in size; at the end of the event it comes to be bigger than at its beginning.) When pod-attaches to such verbs, it specifies that the degree to which the property comes to hold of the participant at the end of the event is relatively low.

Examples: podtajat' (pod- + melt, melt a little bit / incompletely), podrasti (pod+ grow (up), grow (up) a little bit), podzabyt' (pod- + forget, forget slightly, not completely), podgoret' (pod- + burn, to burn slightly), podmoknut' (pod- + get-wet, get slightly wet (not to be thoroughly soaked)), podsoxnut' (pod-dry) 'get somewhat drier', podgnit' (pod-rot) 'become tainted', podustat' (pod-get-tired) 'to get somewhat tired'.

\section{Stative pod}

The last type of pod- that I will mention in this section is not productive, and is found with a small number of verbs. Despite this fact, I believe this use is worth discussing because it illustrates the contribution of the prefix in a straightforward way.

Stative pod-is found with verbs that are not eventive, but rather denote a state whereby a certain gradable property holds of their argument. The function of the prefix is to indicate that the property in question holds of the argument to a relatively low degree. An example would be the verb podtašnivat', derived from the prefix pod-and the verb tošnit' 'nauseate'. The resulting verb means 'nauseate slightly'. Importantly, the verb does not have a perfective form, a fact that is related to its purely stative nature. However, an attachment of a prefix normally results in a formation of a perfective verb. As a result, pod-can only attach to this 
root in combination with a secondary imperfective suffix - va. Thus, we deal with a situation whereby a prefix can only appear in an imperfective verb with a stative semantics. Even though such cases are relatively rare, their existence constitutes additional evidence against the treatment of prefixes as semantic perfectivizers.

The same holds for podnyvat' (ache slightly), derived from the prefix pod-, the suffix - $v a$ and the stem ny- (the verb is used only in spoken, informal language). The more basic verb nyt', 'to moan' under its literal meaning, can also be used with the meaning 'to ache (slightly)'. The attachment of pod-indicates an even lower intensity of the pain. Stative pod-is further illustrated in such verbs as podvanivat' (pod- + stink), 'to stink' (not too heavily) and its synonym podpaxivat' (pod- + smell).

While this type of pod-is highly restricted, its use is sometimes extended in informal speech to stems with which it cannot combine in the more formal or standard dialects (even spoken ones). Some examples from the internet are provided in (6). It is very likely that the speakers of these sentences would say upon second thought that the verbs in question do not exist. Still, such examples are interesting as they illustrate the speakers' ability to use the prefix productively, in predicted ways which reveal the speakers' implicit understanding of the function of the prefix.

(6) a. posle pročtenija otvetov menja stalo PODZNABLIVAT'

after reading answers me started pod-chill

'After having read the answers, I started to feel a slight chill.'

http: //forum. ozpp.ru/showthread.php?t=57117\&page=12

b. golova tože možet PODBALIVAT'

head too may pod-ache

'The head may ache slightly, too.'

http: //forum. antivsd.ru/index.php?topic=3174.0

c. Včera začesalsja glaz, vtoroj $\mathrm{k}$ noči načal

yesterday started-itching eye second toward night started

PODČOSYVAT'SJA.

pod-itch

'Yesterday an eye started itching; the second one started itching slightly by night.'

http://club.passion $\cdot r u / v i e w t o p i c \cdot p h p ? t=158028 \& p o s t d a y s=$ o\&postorder=asc\&start $=405 \&$ sid $=$

\section{[2.2] The Prefix pod-: A Unified Analysis}

I propose that all the uses of pod- listed above share a substantial meaning component, which can be formulated within a framework that relates events to scales and degrees on those scales. More precisely, pod-specifies that the reported event (or some aspect of this event) reaches a relatively low degree $d$ on a certain scale. 


\begin{tabular}{lll}
\hline Type of pod- & Example & Scale \\
\hline $\begin{array}{l}\text { pod- of limited change } \\
\text { stative pod- }\end{array}$ & $\begin{array}{l}\text { podgoret' (burn slightly) } \\
\text { podtašnivat' (nauseate slightly) }\end{array}$ & $\begin{array}{l}\text { property scale } \\
\text { property scale } \\
\text { (physical experience) }\end{array}$ \\
$\begin{array}{ll}\text { pod- of approaching } \\
\text { vertical pod- }\end{array}$ & $\begin{array}{l}\text { podjexat' (approach by driving) } \\
\text { podstelit' (lay under) }\end{array}$ & $\begin{array}{l}\text { path scale } \\
\text { path scale (verticality) }\end{array}$ \\
\hline
\end{tabular}

TABLE 1: Uses of the prefix pod-

The degree $d$ is relatively low in the sense that it is lower than another degree $d_{s}$ which is either contextually supplied or provided by a linguistic expression present in the sentence. The unified semantics of pod- has been formalized in (3), repeated below as (7):

$$
\llbracket p o d-\rrbracket=\lambda P \lambda d \lambda x \lambda e \lambda d_{s} \cdot\left[P(d)(x)(e) \wedge d<d_{s}\right]
$$

The different uses of the prefix differ primarily in terms of the scale relative to which they restrict the event - and, therefore, in the precise component of the event that is restricted. Also, some uses differ in terms of the source and nature of the standard of comparison, and in the precise relation between the degree $d$ and the event (e.g. with pod- of limited change and pod- of approaching, $d$ is associated with the endpoint of the event, whereas with stative pod-, it is linked to the state as a whole.)

An important consequence of the proposal made in this section is that the multiple types of pod-discussed above should not be treated as an instance of homonymy. We deal with a single prefix, rather than a set of different morphemes that happen to be phonologically identical. It seems likely that polysemy should be ruled out on the same ground. We do not deal with multiple meanings of the item, but rather with a single meaning, indeterminate to a certain degree, with the precise interpretation largely predictable on the basis of the environment in which the prefix appears. Still, some features may characterize one use but not the others (see discussion below), a factor that could be used to argue for a polysemy approach (but definitely not homonymy). And of course, we should allow for a certain degree of idiosyncrasy given that this is a derivational morpheme. But overall, by analogy with Součková's (2004b) claim about the prefix po- in Czech, we can conclude that in Russian, there is only one pod-.

In what follows, I reconsider the uses of pod- listed in Section [2] and specify the scales relative to which each of the uses imposes the restriction in (7). The range of scales involved is summarized in Table 1. 
pod- of Limited Change

Let us begin with pod- of limited change, observed with such verbs as podtajat' (melt incompletely) and podrasti (grow (up) a little bit). The verbs with which this type of pod-combines lexicalize a property scale (Rappaport Hovav 2008), e.g. the scale of height in the case of rasti ' grow $^{5}$ or the scale corresponding to the property of liquidity (the consistence) in the case of tajat' 'melt'. The prefix specifies that the degree $d$, which an argument of the verb reaches on the property scale AT THE END OF THE EVENT, is lower than the standard of comparison (even though it is higher than the degree associated with the starting point of the event).

I will assume the semantics of degree achievements in (8), which is based on Kennedy \& Levin (2002), with several modifications in accordance with the formal framework adopted in this paper. (9) formalizes the denotation of the complex predicates which contain pod- of limited change.

$$
\llbracket \mathrm{V} \rrbracket=\lambda d_{d}^{\prime} \lambda d_{d}^{\prime \prime} \lambda y_{e} \lambda e_{v} \cdot\left[Q(d)(y)(\operatorname{END}(e)) \wedge Q\left(d^{\prime \prime}\right)(y)(\operatorname{BEG}(e)) \wedge d^{\prime}>d^{\prime \prime}\right]
$$

$\llbracket p o d-V \rrbracket=\lambda d \lambda x \lambda e \lambda d_{s} \lambda d^{\prime \prime} \cdot\left[Q(d)(x)(\operatorname{END}(e)) \wedge Q\left(d^{\prime \prime}\right)(x)(\operatorname{BEG}(e)) \wedge d>\right.$ $\left.d^{\prime \prime} \wedge \boldsymbol{d}<\boldsymbol{d}_{\boldsymbol{s}}\right]$

(where $Q$ is the gradable property lexicalized by the verb, BEG is the function from events to times that returns an event's beginning point

END is the function from events to times that returns an event's final point (Kennedy \& Levin 2002))

The standard of comparison can come from two sources, depending on the type of scale introduced by the predicate. The important distinction is between upper (or totally) closed scales, on the one hand, and open (or lower closed) scales, on the other, in the sense of Kennedy \& McNally $(2005)^{6}$. Upper closed and totally closed scales are scales that have a maximal element. For instance, consider a gradable adjective like full. A vessel can filled to different degrees, but if it is completely full, then it is filled to a maximal degree that cannot be further exceeded. In contrast, lower closed and open scales lack such a maximal element. Such a scale is introduced by the adjective high: no matter how high a given entity is, it is always possible to conceive of something that is yet higher, i.e. the scale is not associated with an upper boundary, or a maximal value.

It turns out that the type of scale plays a crucial role in determining the standard of comparison that is invoked by pod-. If the verbal stem lexicalizes a totally or upper closed scale, then the comparison is to the maximal degree on this scale.

[5] For the Russian verb, this is most likely to be the scale of height, although this could be a scale of size, too.

[6] See Filip (2008) for a detailed discussion of the relation between the upper boundary of closed scales and perfectivity and maximalization. 
The predicate with pod- denotes a set of events whose participant fails to reach this maximal degree. To illustrate, tajat' (melt) introduces a closed scale whose maximal degree corresponds to the state of being absolutely liquid. Podtajat' denotes a set of events in whose course an object becomes more liquid than it was at the beginning of the event but still fails to become absolutely liquid. Importantly, the change of state may be quite considerable, as long as by the end of the event the object fails to completely turn into the liquid state.

In turn, if the predicate introduces an open (or lower closed) scale, a scale that does not have a maximal element, then the degree reached by the participant is required to be lower than some contextually specified expectation value or norm. For example, the property scale lexicalized by rasti (grow) is open. The subject of podrasti is entailed to reach a higher degree on this scale than it used to have, but the degree it reaches is still lower than a contextually specified standard. In other words, in the course of the event, the subject becomes higher or taller than he used to be, but he still does not become truly high/tall (with the denotation of high/tall being contextually determined).

A strongly related fact is that, as pointed out by Filip (2008), what counts as a MAXIMAL event is determined by the context if the associated scale is open, and by the upper bound of a scale if it is closed.

To sum up, we have seen that pod- of limited change applies to a property scale and relates the event to a degree that is lower than either the maximal element on the scale (if the latter exists) or a contextually specified value.

\section{pod of Approaching}

Let us now turn to pod- of approaching. This prefix relates an event participant to a degree on a path scale. A path scale orders objects located along a path in accordance with their remoteness from the source. pod-specifies that the maximal element on the path scale reached by the moving object in the course of the event is lower than the element specified in the direction phrase. Thus, here, it is the direction phrase that provides the standard of comparison. Part of the semantics of verbs of motion that contain this type of pod-can be formalized as in (10), by relating to the gradable property in which the subject undergoes a change (along the line of Kennedy and Levin's approach in (8)). The gradable property would then be advancement along a path (ADV).

$$
\lambda d \lambda d^{\prime} \lambda x \lambda e \lambda d_{s} \cdot\left[\operatorname{ADV}(d)(x)(\operatorname{END}(e)) \wedge \operatorname{ADV}\left(d^{\prime}\right)(x)(\operatorname{BEG}(e)) \wedge d>d^{\prime} \wedge d<d_{s}\right]
$$

Interestingly, pod- of approaching contributes an additional meaning component. It specifies that the maximal degree reached by the event participant is CLOSE TO the degree contributed by the direction phrase. Thus, at the end of the event, the subject reaches a degree that is lower than but close to the standard of comparison. This meaning component of proximity does not characterize some of 
the types of pod- (e.g. pod- of limited change or pod- of limited contribution (see Section [2.3] below)), a factor that could perhaps be used to argue for a polysemy approach to the prefix. It will be shown in Section [2.4], however, that the proximity component does characterize some uses of pod as a free morpheme (although, again, not all of them). Also, as we will see in the next section, this component is typically associated with vertical pod-. It thus seems that all the uses of pod discussed in this paper share the component of the 'lower than' relation between two degrees; some but not all of them introduce, additionally, a proximity restriction ${ }^{7}$.

Finally, it should be noted that predicates with pod- of approaching may contain an adjunct phrase (headed by the preposition $n a$ ) that specifies the distance between the degree reached at the endpoint of the event and the standard of comparison. Essentially, it provides the difference between the two degrees to which the prefix applies. (As demonstrated by (11-b), the notion of proximity associated with pod- of approaching is context-dependent.)
a. ...on podojdjot $\mathrm{k}$
vam na rasstojanije udara...
he pod-walk ${ }_{\mathrm{FUT}}$ toward you on distance strike $_{\mathrm{GEN}}$
'He will come within hitting distance of you.'
b. ...vrag podojdjot na rasstojanie 80 kilometrov $\mathrm{k}$ Kremlju... enemy pod-walk $\mathrm{FUT}_{\mathrm{FU}}$ on distance 80 kilometers toward Kremlin 'The enemy will come within an 80 kilometer distance of Kremlin.' National Corpus of Russian

\section{Stative pod-}

Stative pod-is found with verbs that denote a state of being characterized by a property that is, to begin with, gradable. The semantics of these verbs can be represented as in (12). It should be noted that this type of pod-is only compatible with a limited range of gradable properties - mainly, properties having to do with physical health, with the exception of smell emission. The prefix thus only combines with verbs that report a physical experience/perception and introduce an experiencer argument, either explicitly or implicitly.

$$
\llbracket \mathrm{V} \rrbracket=\lambda d \lambda x \lambda e \cdot[P(d)(x)(e)]
$$

where $P$ is the property lexicalized by the verb, and $x$ stands for either an experiencer argument or, with such verbs as vonjat' (stink), for the stimulus

[7] In the case of pod- of approaching, the proximity component may be intuitively motivated in the following way. It only makes sense to describe an endpoint of a motion event relative to a point that has not been reached if the moving object got close to this point. Otherwise, using this point as a landmark would be too uninformative. 
pod-applies to the degree argument which is present in the semantics of the stem to begin with, and specifies that the degree is lower than the standard of comparison. Note that in this case, the degree is not linked to the endpoint of the eventuality, but rather to the state in general. This results from the fact that here, pod-does not apply to verbs that denote a change (in contrast to the case of pod- of limited change).

$$
\llbracket \text { pod-V } \rrbracket=\lambda d \lambda x \lambda e \cdot\left[P(d)(x)(e) \wedge d<d_{s}\right]^{8}
$$

With stative pod-, the standard of comparison consistently corresponds to a contextually supplied value. It is world knowledge together with the more specific context of utterance that determines which degree of stinking or aching is judged as high and which, as low.

\section{Vertical pod-}

Finally, I turn to vertical pod-, which is associated with the meaning '(from) under'. Let us begin with the preposition pod (under), from which this use of the prefix receives its meaning. This preposition, similarly to many others, encodes a certain spatial relation between two objects, a theme, figure, or trajector (depending on one's terminology) and a reference object / ground / landmark (cf. Janda (1988); Levinson (2001); Rappaport Hovav (2009), and references therein). This relation can be treated as a relation between two degrees on a scale. The scale can be conceptualized as a path scale, since it imposes an ordering relation on objects in accordance with their spatial configuration. The path is formed by a "set of contiguous locational points between the theme and [the reference object]" (Rappaport Hovav 2009, 7). In the case of the preposition pod and its English counterparts under and below, this scale is concerned particularly with verticality. It orders points that are spatially located under one another, with a lower position corresponding (iconically) to a lower degree on the scale. The prepositions specify that a certain object (the theme) receives a lower value than another one (the reference object) on this scale. A sentence of the form $x$ is below $y$ relates $x$ to a degree on the vertical path scale which is lower than the degree corresponding to the location of $y$. The fact that these prepositions introduce a scale is supported by their compatibility with degree modifiers (cf. Rappaport Hovav 2009, 7), e.g. three meters below, five meters under, far below, $v$ vos'mi metrax pod (in eight meters under).

I propose that the vertical pod-contributes the same scale as the preposition pod and specifies the same relation along this scale. This is the only use of the prefix that contributes a scale of its own (rather than applying to a scale contribut-

[8] I am using $e$ as a variable over eventualities of any kind, including both events and states. Alternatively, the variable $s$ could be used to indicate that we deal with state predicates. 
ed by the environment). This is the scale inherited from the preposition from which the prefix is derived. As shown above, vertical pod- has evident signs of a lexical prefix: its contribution is not transparent and varies from verb to verb. It is important that despite this fact, the prefix is characterized by the meaning component in (7). It makes sure that a certain degree associated with the event is lower on the scale of vertical configuration than another degree. A point on this scale occupied by an argument at some stage of the event is lower than the standard of comparison. The more precise relation between the reported event and the two degrees in question depends on the particular verb involved since, as we have seen, the contribution of the prefix varies to a certain degree with the stems it attaches to. To illustrate, verbs like podstelit' 'lay $x$ under $y$ ' or podnyrnut' 'dive under' denote a set of events which result in one of their participants located under another object. (The latter object is normally referred to by a linguistic expression). Here, the result state is one whereby an argument occupies a certain degree on the (vertical) path scale which is lower than the standard of comparison.

Note that the proximity component discussed above with respect to pod- of approaching is present here, too. The object that undergoes motion is expected to end up in a position that is close to the standard of comparison. The proximity component is also present with the second type of vertical pod- discussed above, the one that indicates motion upward (e.g. podprygnut' 'jump upward'). Plungyan $(2001,105)$ points out that verbs of this type can only denote events in whose course the object does not move too far from the source. As a result, the event of motion is localized relative to the source. Apparently, that is why the prefix applies to the degree that corresponds to the source location and is thus associated with the beginning of the event. Here, it is the source that is entailed to occupy a relatively low position on the vertical path.

\section{[2.3] pod- of Limited Contribution}

In this section, an additional sub-meaning of pod-is discussed. I will relate to this use as pod- of limited contribution. Similarly to vertical pod-, this is a lexical prefix whose attachment is not fully productive and whose semantic contribution is not always transparent and varies, to a certain degree, from verb to verb and even from context to context. It is therefore interesting to see that in spite of these properties, this use is, too, characterized by the meaning component represented in (7). It, too, associates an event with a degree that is lower than a standard of comparison.

pod- of limited contribution can be roughly divided into two main subtypes, podof accompanying and pod- of addition, briefly introduced below.

pod- of accompanying is illustrated in (14): 


$$
\begin{array}{lll}
\text { podpet' } & \text { podsvistet' } & \text { podygrat' } \\
\text { pod-sing } & \text { pod-whistle } & \text { pod-play } \\
\text { accompany in singing } & \text { accompany in whistling } & \text { play up to / accompany, vamp }
\end{array}
$$

With this type of pod-, a verb denotes a set of P-events each of which is secondary in the sense that it makes a limited contribution to a more basic P-event (where $\mathrm{P}$ is the event property denoted by the stem). For instance, a sentence with the verb podpe(va)t' denotes an event of singing which is secondary relative to a more basic, major singing event.

\begin{tabular}{|c|c|c|}
\hline $\begin{array}{l}\text { podrisovat' } \\
\text { pod-draw } \\
\text { touch up / } \\
\text { add an element } \\
\text { to a picture }\end{array}$ & $\begin{array}{l}\text { podkupit' } \\
\text { pod-buy } \\
\text { buy some more }\end{array}$ & $\begin{array}{l}\text { podlit' } \\
\text { pod-pour } \\
\text { pour some more }\end{array}$ \\
\hline $\begin{array}{l}\text { podkrutit' } \\
\text { pod-twist } \\
\text { twist some more }\end{array}$ & $\begin{array}{l}\text { pod"jedat' } \\
\text { pod-eat } \\
\text { eat remnants }\end{array}$ & \\
\hline
\end{tabular}

pod- of addition is exemplified in (15):

For instance, the verb podrisovat' can be used when a picture has already been drawn by the time of the reported event, and the subject adds something to the picture. The subject may or may not be the agent of the main drawing event. In turn, the verb podkupit' means roughly 'to buy (some) more'. For instance, podkupit' saxaru 'to buy some more sugar' can be uttered if the subject has some sugar at home and buys some more sugar, to be added to the original quantity. The amount that is bought is likely to be lower than the already available quantity. Note that the event of podkupit' need not be preceded by another buying event. The original sugar may have been obtained in a different way, for example brought by a neighbor'. A somewhat different example is pod"jedat' (pod-eat), which means roughly 'to eat remnants'. This verb is used to report an event whose agent eats stuff that remains after another, presupposed, eating event. No information is provided regarding the relative quantity of stuff eaten in the course of the presupposed event and in the course of "pod-eating". Suppose, for example, that a king eats a very small amount of food served on the table, and after he leaves, the servants eat all the rest. Under this scenario, the verb pod'jedat' can still be used to describe the event of eating performed by the servants.

[9] The case is analogous with such items as more in a sentence like I bought (some) more sugar: the presupposed eventuality need not instantiate exactly the same event property as the asserted one (cf. Greenberg (2009) and references therein). 
Thus, verbs with pod- of addition presuppose a certain state of affairs, which may but need not be obtained as a result of a past event denoted by the root verb. The prefixed verb denotes an event which makes a further contribution to this state, for instance, by making more stuff undergo the change of state denoted by the stem. Intuitively, the result of the reported event is viewed as a relatively low contribution to a more general, presupposed state of affairs.

It can be concluded that with both pod- of accompanying and pod- of addition, the reported eventuality is conceptualized as SECONDARY, as making a RELATIVELY Low contribution to a presupposed situation. As pointed out by Plungyan (2001, 110), "the prefix pod-introduces an admittedly reduced, "diminished" realization of the original situation" (my translation).

To make things more precise, we have to distinguish between three eventualities: the entailed event $\left(e_{\mathrm{E}}\right)$, the presupposed event $\left(e_{\mathrm{P}}\right)$, which either precedes $e_{\mathrm{E}}$ or temporally overlaps with it, and a more general, unifying eventuality $\left(e_{\mathrm{UN}}\right)$ that includes both $e_{\mathrm{E}}$ and $e_{\mathrm{P}}$ and can sometimes, but not always, be treated as their sum $e_{\mathrm{E}} \sqcup e_{\mathrm{P}}$. (In this sense, the meaning of pod- has much in common with the additive more, whose semantics has been argued by Greenberg (2009) to involve three eventualities - the entailed event, the presupposed one (which either precedes the entailed one or is contemporaneous with it) and their sum.)

To illustrate, consider the verb podpe(va)t' (accompany in singing). Here, $e_{\mathrm{E}}$ is the accompanying event performed by the subject, $e_{\mathrm{p}}$ is the major singing event performed, most probably, by a different individual (who is accompanied by the subject and can be referred to by a dative DP), and $e_{\mathrm{UN}}$ is the overall singing event whose participants include both the major singer(s) and the ones who sing along $^{10}$. A somewhat different example is provided by the VP podkupit' saxaru (buy some more sugar). $e_{\mathrm{E}}$ is an event of sugar-buying performed by the subject, including, crucially, the result state of the subject having the obtained sugar. $e_{\mathrm{P}}$ is a temporally preceding event whereby an already available amount of sugar has been obtained (together with its corresponding result state). $e_{\mathrm{UN}}$ here is the sum $e_{\mathrm{E}} \sqcup e_{\mathrm{p}}$.

How is the uniform contribution of pod-, represented in (7), revealed under this use? I propose that the type of pod-discussed in this section measures the contribution of $e_{\mathrm{E}}$ to $e_{\mathrm{UN}}$ (or, more precisely, it relates to the degree to which an agent of $e_{\mathrm{E}}$ contributes to $e_{\mathrm{UN}}$ by performing $e_{\mathrm{E}}$.) The standard of comparison is in this case provided by the presupposed eventuality: this is the degree to which (a participant of) $e_{\mathrm{P}}$ contributes to $e_{\mathrm{UN}}$. The contribution of $e_{\mathrm{E}}$ is entailed to be lower than that of $e_{\mathrm{p}}$. Hence the intuition that the asserted event has a secondary status: its contribution to a more general state of affairs is lower than that of a presup-

[10] Note that here, $e_{\mathrm{UN}}$ cannot really be treated as the sum $e_{\mathrm{E}} \sqcup e_{\mathrm{P}}$; and neither $e_{\mathrm{E}}$ nor $e_{\mathrm{P}}$ constitute stages of $e_{\mathrm{UN}}$ in the sense of Landman (2008), since they are not cross-temporally identical with it; still, the more encompassing relation of inclusion holds: $e_{\mathrm{UN}} \subset e_{\mathrm{E}} \wedge e_{\mathrm{UN}} \subset e_{\mathrm{P}}$. 
posed eventuality. This meaning component can be half-formally represented as in (16) (the presupposed part is underlined):

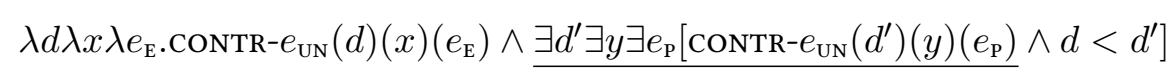

However, the notion of contribution is, obviously, vague and indeterminate. What does it mean for a person $x$ to make a lower contribution to a certain eventuality than a person $y$ ? A participant may contribute to an event along various parameters or dimensions, and it is along such specific dimensions that contributions of different participants are ultimately evaluated and compared. To illustrate, one's contribution to an eventuality can be measured according to the amount of stuff that one produces or causes to undergo a change of state. Alternative dimensions may include, for instance, loudness (of one's singing), or the prominence of the role played by an event participant (relative to the roles of the others). A number of specific examples are provided below. Over all, we can treat contribution as a multidimensional property, which consists of (and can, thus, be measured along) multiple parameters. pod- of limited contribution entails an existence of a salient parameter, or dimension, along which the agent of $e_{\mathrm{E}}$ makes a lower contribution to $e_{\mathrm{UN}}$ than the agent of $e_{\mathrm{p}}$. This dimension can be represented by a specific scale which contains the two compared degrees.

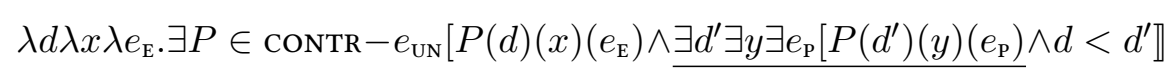

The notion of contribution is thus indeed underspecified, and I believe that the uniform meaning of pod- of limited contribution is indeed underspecified in the way predicted under (17). The precise dimension along which contribution is compared varies from stem to stem and with some verbs, from context to context. The choice of the specific dimension depends, among other factors, on the lexical semantics of the verb, on scenarios conventionally associated with the kind of eventuality it denotes, and on the context. For instance, the verb podpe(va)t' (podsing) leaves it up to the context to determine the precise dimension of contribution. Suppose that during a party, somebody plays a guitar and several people sing. One could choose to say that one of them podpevajet if the person only sings some, relatively small, parts of the song. In this case, we can say that the contribution is measured according to the number of lines that is sung by each of the participants. The contribution of the subject is lower than that of other participants, because (s)he sings fewer lines (or stanzas). Alternatively, the prefix podmay be used if the subject sings very quietly (crucially, appreciably more quietly than the others.) Here, it is along the scale of loudness that his contribution is measured. Because the subject sings quietly, his contribution to the singing event is conceptualized as lower than that of other participants. Finally, suppose that a song is being performed by a chorus. Such an eventuality is associated with a set 
of conventionally determined roles (e.g. soloist, second part, etc.) These roles, in turn, are (conventionally) ordered, subject to a particular ranking (with the role of a soloist being the highest in the hierarchy.) The verb podpevat' can be used to indicate that the subject receives a relatively low role in terms of this ranking (more precisely, his role is lower than that of the soloists who are presupposed to participate in the singing event.)

For other verbs, the parameter along which contribution is measured is lexically determined, rather than context-dependent. For instance, with the stem jest' (eat), it is measured according to the ranking of the social roles taken by the participants (one has the 'higher' role of the person for whom the food has been cooked; the other one receives the 'lower' role of a person who is allowed to eat whatever is left by the former.)

To sum up this section, the semantics of verbs that contain pod- of limited contribution is not purely compositional and is, to a considerable degree, contextdependent. I have argued that despite this complexity, this instance of pod- exhibits the meaning component represented in (7) above, which unifies it with the other uses of the prefix. Under this use, too, the asserted eventuality is associated with a degree on a scale that is entailed to be lower than the standard of comparison.

\section{[2.4] Generalizations and Predictions}

The Meaning of pod-Depends on the Semantics of the Stem

The unified treatment of pod-argued for above allows us to make predictions regarding the meaning of the prefix on the basis of the environment in which it appears. Predictability is somewhat restricted due to the presence of certain lexical uses whose contribution is not purely transparent. Still, a number of generalizations can be made, including the following:

(i) pod- of limited change is obtained with those stems that denote events of change and lexicalize a property scale. The prefix applies to the scale contributed by the stem, which results in the limited change interpretation. Furthermore, the standard of comparison, too, depends on the environment, or more precisely, on the kind of scale lexicalized by the verb. If this is an upper closed scale, the standard of comparison will correspond to its maximal element (the degree which an argument reaches on this scale will be entailed to be lower than the maximum.) If this is an open scale, the standard of comparison will be a contextually supplied standard

(ii) pod- of approaching is obtained with those stems that lexicalize a path scale. Again, the interpretation is a product of the prefix applying to the scale contributed by the verb. 
(iii) It is somewhat more difficult to predict the attachment of vertical pod-, due to its restricted productivity and "highly lexical" nature. Typically, this type of pod- is available with those stems that denote events of motion or placement and which are especially easily conceptualized as involving motion directed either upward (as in podprygnut' (jump upward)) or to a position that is located under a certain object (e.g. podstelit' (lay under), podpolzti (crawl under), podlezt' (creep under), podnyrnut' (dip under)). As stated above, the scale of vertical configuration is contributed by the prefix, rather than its environment, but the stem must be semantically compatible with this scale

(iv) If the stem is semantically compatible with the vertical path that can be introduced by pod-, and also contributes a scale of its own, an ambiguity may result, since the prefix may apply to each of the potentially available scales. To illustrate, the verb podpolzti is ambiguous: it may mean 'to approach by crawling' (18-a) or 'to crawl under' (18-b), depending on whether the prefix applies to the path scale introduced by the verb or contributes and applies to a vertical path scale.
a. Jaščerica podpolzla $\mathrm{k}$ derevu. lizard pod-crawled toward tree 'The lizard crawled to the tree.'
b. ...[dog]... podpolz pod slomannyj divan. Great-Dane pod-crawled under broken sofa '...the Great Dane crawled under a broken sofa.' Kanžinsky, "Biologičeskaja radiosvjaz" ("Biological Radio Commu- nication") http://www.teatr-zverey.ru/test_new/kanjin_1.html

The same kind of ambiguity holds for podprygnut' (pod-jump).

Further, the choice of scale to which the prefix applies appears to be subject to the following hierarchy (which is evoked in those cases when more than one scale is in principle available):

$$
\text { vertical path scale }>\text { scales lexicalized by the verbal stem }>\text { contribution scales }
$$

As a rule, the prefix will apply to the scale that is highest on the hierarchy out of the ones that are available. (This is a strong tendency which may be overruled by lexically fixed properties of a given verb.) One prediction is that whenever the prefix contributes a scale of its own, it is to this scale that it will apply. This is indeed the case: whenever pod-contributes the 'vertical path' meaning, it is to the vertical path scale that it applies. And whenever the prefix applies to a different scale, it can be seen that the vertical path meaning is not introduced. For instance, 
in (20) below, the vertical path scale is not introduced: no information is provided regarding the relative positions of objects on this scale.

(20) Lena podošla/ podbežala/ pod"jexala k ploščadi.

Lena pod-walked pod-ran pod-drove to square

'Lena approached the square (by walking / running / driving).'

Once the vertical path scale is contributed by the prefix, it is to this scale that it must apply.

The situation is slightly more complex with the choice between contribution scales and scales lexicalized by the stem. In many cases, if the prefix does not contribute a scale but the verbal stem does, pod- will apply to the scale provided by the stem (rather than measuring contribution). For instance, the verb podojti (podwalk) does not have the meaning of 'to walk a little bit more', as demonstrated in (21). Here, the stem lexicalizes a path scale, and the prefix has to apply to this scale, rather than a scale of contribution.

(21) Ja šla po ulice. *Potom podošla eščo nemnogo.

I walked on street then pod-walked more a-little intended meaning: 'I walked down the street. Then I walked a little bit more.'

An exception is constituted by a subset of verbs that lexicalize a property scale. With some of these stems (apparently with most of them), pod- can only apply to the property scale (e.g. podtajat'). But with others, it seems that the prefix may choose whether to apply to the property scale or to a scale of contribution. For instance, the verb podlečit' (pod- + cure) may be used to report curing events whereby the health of the patient improves but not completely. Here, the prefix applies to a property scale. But, as pointed out by Plungyan $(2001,111)$, the verb may be used to mean roughly 'to give a short / non-aggressive / reduced course of treatment'. Under this reading, the prefix seems to apply to a contribution scale, as the event is asserted to make a relatively low contribution to the overall health state of the patient.

Crucially, however, the ranking in (19) still holds. Once a property scale is available, the prefix may apply to this scale only or to this scale as well as to the contribution scale. However, the prefix will not apply to a contribution scale alone, without having the alternative of applying to the property scale. Thus, an asymmetry between the two scale types is still present.

On the intuitive level, the hierarchy in (19) can be understood in the following way. If the prefix contributes its own scale, it will denote a relation on this scale. If it does not, the pod-verb will denote a set of events that are, in a certain sense, limited. If the stem lexicalizes a scale, then the limitation will be relativized to 
this scale: the event is limited in the sense that it fails to reach a certain degree on this scale. If the stem does not provide a scale, then the event will be interpreted as successfully completed. However, it will be understood as limited in comparison with another, presupposed, eventuality, because the latter makes a higher contribution to some more encompassing situation.

\section{[2.5] Non-Existent Interpretations}

In addition to making predictions regarding the contributions available to pod- on the basis of its environment, the proposed analysis allows us to deal with those meanings that pod- CANNOT have. The degree framework makes it possible to list some scales to which pod- cannot apply and account for the corresponding gaps in its use.

First of all, is can be seen that pod- cannot apply to the volume/extent scale associated with the object. This results in non-existence of such VPs as *podčitat' knig (pod- + read books), meaning 'to read few books', *pod"jest' jablok (pod- + eat apples), 'to eat a small amount of apples" ${ }^{11}$.

Secondly, pod-cannot apply to the time scale. For example, there does not exist a verb *podstojat' (pod- + stand), whose meaning would be expected to be 'to stand for a short while'. Analogously, one cannot say *podbolet' (pod- + be-sick) with the intended meaning of 'to be sick for a short while'. Thus, pod- cannot measure an event by applying to the time scale and asserting that the duration of the event denoted by the stem is shorter than some standard of comparison.

These restrictions can be accounted in the following way. It is generally accepted in the current literature on the topic that different verbal prefixes in Slavic occupy different structural positions (cf. e.g. Romanova (2004); Ramchand (2004).) For instance, superlexical prefixes appear higher in the structure than the lexical ones, which accounts for many of the differences between the two groups. I remain agnostic as to the precise syntactic position taken by pod-, but I propose that it applies locally to the verbal stem, so that other syntactic constituents remain outside of its scope. (In this respect it differs from some lexical prefixes which have been argued to take the object NP as their complement, or at least to include it in their scope, cf. Filip (2005); Ramchand (2004)). As a result, the prefix

[11] Such VPs as podkupit' saxaru (pod-buy sugar) or pod"jedat' jedu (pod-eat food) do not constitute an exception to this generalization since, as discussed above, pod-in these cases measures the contribution of $e_{\mathrm{E}}$. If it measures quantities of stuff, this is an indirect result of measuring contribution. This view is supported by the fact that in the absence of the 'limited contribution' reading, i.e. when the entailed event is not compared to a presupposed one, pod-clearly cannot apply to a volume/extent scale and measure quantities of stuff (see examples above). Further, with such phrases as pod"jedat'jedu, no information is provided regarding the amount of food eaten in the course of the event. The amount could be big both in comparison with the presupposed eating event and relative to a contextually provided expectation value. 
can only apply to those scales that are already introduced at the level of the pod- $V$ constituent ${ }^{12}$.

Thus, it can apply to a scale that is lexicalized by the verb, e.g. a path scale or a property scale. It can also contribute a scale of its own, as is the case with vertical pod-. However, the prefix cannot apply to a scale that is introduced at a higher level of derivation. For instance, the time scale is not lexicalized by the verb; rather, it is introduced at a higher structural level (possibly in the area of AspP). This scale is thus not available for pod- to apply to. The case is similar with the volume/extent scale. As argued by Rappaport Hovav (2008), this scale is not lexicalized by the verb but rather contributed by its object. As a result, it, too, is not accessible to the prefix.

\section{[2.6] Non-Verbal pod-}

Further evidence of the scalar nature of pod-comes from the uses of this item not as a verbal prefix. In the following subsections, I discuss certain uses of pod as a free morpheme and the prefix pod-that attaches to nouns.

\section{Pod as a Free Morpheme}

We have seen that the standard spatial meaning of the preposition pod can be represented in scalar terms (cf. Section [2.2]). The free morpheme pod is interpreted as a relation between two degrees under at least two additional uses, quantificational and temporal.

\section{a) Pod with Quantity Expressions}

Firstly, the morpheme pod can combine with quantity expressions, mainly numerals. The resulting [pod Num] constituent denotes a quantity that is close to, but somewhat lower than, the quantity denoted by the original numeral. Two examples are provided in (22):

[12] The situation is not quite clear in those cases when pod-combines with an already prefixed stem, e.g. podvy-pit' 'take a drop', pod-u-stat' 'get somewhat tired' and pod-za-rabotat' 'earn a little bit'. Since lexical prefixes cannot stack, pod- that appears in such verbs is more likely to be a superlexical (or maybe an intermediate) prefix, which as such is expected to attach at a higher structural position. Still, even with these verbs, the scale to which the prefix applies appears to be contributed by the verbal stem. For instance, ustat' 'get tired' contributes the property scale of weariness. Vypit' under the relevant meaning of drinking alcohol contributes the scale of drunkenness. Pod- applies to this scale, rather than to a volume/extent scale contributed by an object. This can be seen from two facts. First, the verb podvypit' does not easily combine with an object at all. Second, what the verb measures is the state of the subject's drunkenness, and not the amount of alcoholic beverages that have been drunk. The subject is entailed to be drunk but not dead drunk; the verb provides no information about the amount of alcohol he has consumed. Finally, the verb podzarabotat' may seem to measure the object (the amount of money). However, the prefixed stem zarabotat', meaning 'to earn', seems to contribute the scale corresponding to the amount of the income on its own, independently from whether it combines with an object or not (in fact, the object is perceived as redundant in the phrase zarabatyvat' den'gi 'earn money'.) All these facts suggest that even when pod-combines with a prefixed stem, it applies to the scale that is made available by the verb, rather than by additional constituents. 

a. Ej pod 80 .
she $_{\text {DAT }}$ pod 80
'She is slightly less than 80 years old.'
b. V etoj glave pod 40 stranic.
in this chapter pod 40 pages
'This chapter is a little less than 40 pages long.'

(22-a) entails that the subject is slightly less than eighty years old (probably 78 or 79). According to (22-b), the length of the chapter is slightly less than 40 pages; it is maybe 37 or 39 pages long. Under this use, pod applies to a scale that orders numbers. A certain degree on this scale is entailed to be slightly lower than the degree contributed by the numeral. This way, the degrees corresponding to the woman's age in (22-a) and the length of the chapter in (22-b) are entailed to be slightly lower than the values provided by the numerals that complement the preposition.

b) Pod with Temporal Expressions

Secondly, a scalar interpretation is sometimes invoked when pod combines with a temporal expression. The event modified by the pod-phrase is then entailed to take place slightly before the time denoted by the original temporal expression. For instance, the expression pod utro (pod morning) in (23-a) is used to refer to the time of day that precedes the morning (possibly 4 or 5 a.m.)

The expression pod Novyj God (pod New Year) can be used to temporally locate events that take place, for instance, on December 29-30, or in the morning of December 31.

It should be noted that this use of pod is not fully productive; in fact, it is highly restricted. The most typical examples are the ones provided in (23). Still, a search in National Corpus of Russian renders a considerable amount of additional examples (e.g. (24)), showing that this use of pod is productive to a certain degree, and is not limited to a number of frozen expressions. The example in (24-c) is interesting since the speaker explicitly specifies what she means by the expression pod zimu (pod winter). The expression is used to pick up a relatively late part of the fall, here, the end of October.
a. pod utro/ pod večer pod morning pod evening
b. pod konec pod end
c. pod Novyj God/ pod Roždestvo pod New Year pod Christmas
d. pod osen' pod fall 
a. ...pod final zadam vam krasivyj vopros ot slušatel'nicy... pod end I-will-ask you beautiful question from auditress 'In the end, I will ask you a beautiful question from our auditress.'

b. Esli už oxota na oligarxov, to pod vybory. if already hunt on oligarchs then pod elections 'If there is a hunt on oligarchs, it takes place before elections.'

c. Možno sejat' osen'ju pod zimu (v konce oktjabrja)... may sow in-fall pod winter in end October 'One may sow in the fall, before the winter (at the end of October.)'

Once again, pod imposes a relation between two degrees, this time on the time scale. The time of the event modified by the PP is entailed to be lower on the scale than the value invoked by the complement of the preposition.

Interestingly, the uses of pod discussed in this subsection involve a proximity meaning component, in addition to contributing the 'lower than' relation between two degrees. As we saw above, this meaning component is also present in the meaning of pod- of approaching. However, it does not characterize most other uses of the prefix pod-, nor does it characterize the preposition pod under its basic spatial meaning. A sentence of the form $x$ is under $y$ does not entail that the distance between $x$ and $y$ is relatively small, as one can, for example, talk about cities located under the blue sky. It thus appears that the proximity meaning component characterizes some uses of pod but not all of them, both when it functions as a verbal prefix and when it appears as a free morpheme.

pod-as a Nominal Prefix

The nominal pod-is a derivational prefix that attaches to nouns. The semantic contribution of this prefix is comparable to that of the prefix sub- in such words as subset or subtype. The nominal pod-indicates a lower level on a taxonomy/hierarchy than the one associated with the stem. Thus, pod-nouns are often hyponyms of their counterparts that do not contain pod-.

$\begin{array}{llll}\text { podvid } & \text { podrazdel } & \text { podpolkovnik } & \text { podderevo } \\ \text { pod-species } & \text { pod-section } & \text { pod-colonel } & \text { pod-tree } \\ \text { subspecies } & \text { subsection } & \text { lieutenant colonel } & \text { sub-tree }\end{array}$

$\begin{array}{ll}\text { podmnožestvo } & \text { podsistema } \\ \text { pod-plurality } & \text { pod-system } \\ \text { subset } & \text { subsystem }\end{array}$

Here again, the function of the prefix can be formulated in scalar terms. The relevant scale orders elements in accordance with their rank in a certain hierarchy or with their level in a taxonomy. The value of the pod-noun on this scale is 
one-level lower than the value associated with the stem. Thus, the 'lower than' relation between two degrees is contributed by this type of pod, too.

\section{[2.7] Pod: A Summary}

To sum up the discussion of the verbal pod-, I have argued that this prefix denotes a relation between two degrees. It specifies that a degree associated with an event (in some cases, the degree reached by an event participant at the endpoint of the event) is lower than the standard of comparison. This approach allowed us to unify different uses of pod-, which were argued to differ primarily in terms of the scale to which the prefix applies. The range of contributions available to the prefix is to a large degree predictable on the basis of the environment in which it appears. Further, the impossibility of certain contributions can be accounted for on the basis of the structural position of the prefix and its semantic scope. Finally, it has been shown that certain non-verbal uses of pod (as a free morpheme and as a nominal prefix) render support to the scalar nature of this morpheme.

\section{[3] THE PREFIX DO-}

The prefix do- is derived from the preposition do, which can be translated as to, until, or as far as. This prefix can often be translated as finish, since it relates the event denoted by the stem to a certain finishing point. It is referred to as a terminative prefix by Filip (2008), who points out that the prefix relates to an endpoint on a certain scale, with the details of the latter being determined by the environment in which the prefix appears.

The attachment of this prefix is productive, and its contribution is transparent. These properties, together with the fact that the prefix has a clearly aspectual meaning, suggest that the prefix is superlexical. However, similarly to lexical prefixes, it is perfectly compatible with secondary imperfectivization (e.g. dočitat' - dočityvat' (finish reading)). This duality is captured by Tatevosov (2008), who argues that do- is an intermediate prefix.

Uses of this prefix are illustrated in (26).

(26) a. Vasja dočital knigu.

Vasja do-read book

'Vasja finished reading a/the book.'

b. Vasja dočital knigu do konca/ do serediny.

Vasja do-read book do end till middle

'Vasja finished reading the book / half of the book.'

c. Vasja dobežal do magazina.

Vasja do-ran do store

'Vasja reached the store by running.' 
d. My dosideli tam do utra.

we do-sat there do morning

'We sat there till the morning.'

e. ...ja eščo ne doros do amerikanskogo pensionnogo vozrasta...

I yet NEG do-grew do American pensionable age

'I have not yet reached the American retirement age.'

(National Corpus of Russian)

f. Dotajal poslednij sneg $\mathrm{v}$ ovragax.

do-melted last snow in ravines

'The last snow finished melting in (the) ravines.'

For instance, (26-a) asserts that Vasja finished reading the book. (For the sake of comparison, its non-prefixed counterpart Vasja čital knigu entails that Vasja was engaged in reading the book but provides no information as to whether the event reached its natural endpoint or not.) A PP headed by the preposition do can be added to this sentence (26-b), the resulting sentence entailing that the reading event reached the point specified by the do-phrase. If the phrase is do serediny (to middle), then the sentence entails that the middle of the book was successfully reached in the course of the reading event, i.e. Vasja finished reading half of the book. (26-c)-(26-f) constitute additional illustrations of the use of this prefix; some of them contain a do-phrase and some do not.

I propose that the prefix do- introduces the relation of identity between two degrees. It identifies the degree associated with the endpoint of an event (i.e. a degree reached by some event participant at the endpoint of the event) with a standard of comparison. This way, the prefix functions as an event delimiter, as it contributes information regarding the endpoint of an event (and, more generally, introduces the endpoint into the picture ${ }^{13}$.)

$$
\lambda P \lambda d \lambda x \lambda e \lambda d_{s} \cdot\left[P(x)(e) \wedge Q_{P}(d)(x)(\operatorname{END}(e)) \wedge d=d_{s}\right]
$$

where $P$ is the event property denoted by the verbal predicate, and $Q_{P}$ is the gradable property an increase in which is denoted by the predicate

[13] As discussed by Filip (2008), if the verb is imperfective and receives a progressive interpretation, the resulting sentence does not entail that this endpoint is reached in the actual world. The details of the semantics of such sentences depend on one's more general assumptions on the semantics of progressive and imperfective aspect. For instance, an intensional approach to the progressive originally proposed by Dowty (1979) may be assumed. Under this approach, the imperfective sentences entail that the endpoint is reached in so-called inertia worlds, worlds in which events develop without interruption, but not necessarily in the actual world. In any event, the presence of do- makes sure that an endpoint is introduced into the semantics of the sentence (and identified with the standard of comparison). However, in the presence of an imperfective operator, this endpoint need not be entailed to be reached in the actual world. 
It should be noted that the formula in (27) does not constitute an instance of (1). In fact, the schema in (1) turns out to be insufficient for the purposes of representing the requirements imposed by do- in a sufficiently precise way. More specifically, it does not leave open the possibility of indicating the precise relation between the degree argument $d$ and the event denoted by the verb. This suggests that the semantics in (1) should be slightly modified. I turn back to this issue in Section [4] below.

With the prefix do-, the standard of comparison is often specified by a linguistic expression, in particular, by the do-PP, e.g. do magazina in (26-c). This way, (26-c) reports a running event at the end of which Vasja reaches a point on the path that corresponds to the location of the store. In the absence of such an expression, the source of the standard of comparison depends on the type of scale involved. Here again, the important question is whether the scale is upper closed or not. If the scale is upper closed, then the standard of comparison corresponds to the maximal point on this scale. An event participant is thus entailed to reach this maximal point at the end of the event. For instance, (26-f) asserts that the snow has melted completely. The verb melt lexicalizes a property scale which has a maximal point (corresponding to the state of being absolutely liquid). In the absence of a do-phrase, the sentence entails that the snow, which undergoes a change of state, reaches the maximal point on the property scale (i.e. it completely turns into water) at the end of the melting event. The situation is similar in (26-a). Here, the volume/extent scale introduced by the object knigu is a closed one (the maximal point on this scale corresponds to the book in its wholeness.) The sentence entails that this point was reached at the end of the reading event, namely, that Vasja finished reading the book. However, once a do-PP is added, it overrides the contribution of the maximal point, winning the competition for the status of the standard of comparison. If present, a do-phrase will determine the standard of comparison. As a result, (26-b) with the do serediny variant entails that at the end of the reported event, Vasja completed reading half of the book, rather than the book in its wholeness, i.e. he "reached" the middle of the book.

If do- applies to a scale that is not upper closed, and a do-PP is absent, the context has to be sufficiently rich to determine what counts as the standard of comparison. For instance, a sentence like (28) is somewhat strange out of context. However, it is perfectly acceptable in a context whereby it is known that Vasja had been running towards the store. Then an overt do-phrase is not required, and information regarding the point on the path which Vasja is asserted to reach is recoverable from the context.

Vasja dobežal.

Vasja do-ran 
It can be seen from the examples in (26) that do- can apply to scales with different dimensions, including a scale of volume/extent contributed by the object (as in (26-a)-(26-b)), a path scale (26-c), a time scale (26-d), or a property scale (26-e)-(26-f)). The scale to which the prefix applies depends on the environment in which it appears (Filip 2008, cf.), as is also the case with pod- (and even more so, given that the contribution of do- is purely compositional.) If the verbal stem lexicalizes a scale, it is to this scale that do- will apply. This may be a path scale or a property scale. If the verb itself does not contribute a scale, but it is an incremental theme verb, then the prefix will apply to the scale introduced by the direct object (a volume/extent scale) ${ }^{14}$. If none of these conditions are satisfied, the prefix can apply to the time scale. (Součková (2004a) shows that an analogous hierarchy determines the scale to which the prefix po- applies: it "selects" a time scale only in case no other scale is lexicalized by the VP.)

Finally, let us illustrate the semantics of a sentence that contains the prefix do-, assuming the analysis proposed for this prefix in (27). The logical form of (29) can be represented as in $\left(29^{\prime}\right)$ :

...radiator dogrelsja do 60 gradusov...

heater do-warmed do 60 degrees

'The heater warmed up to 60 degrees Celcius.'

http://forum.ixbt.com/topic.cgi?id=62:15454-113

(29') $\exists e \exists d \exists d^{\prime}[\operatorname{warm}(d)$ (the radiator) $(\operatorname{BEG}(e)) \wedge$

$\operatorname{warm}\left(d^{\prime}\right)$ (the radiator $\left.)(\operatorname{END}(e)) \wedge d^{\prime}>d \wedge d^{\prime}=60^{\circ} \mathrm{C}\right]$

\section{[4] SEMANTICS FOR PREFIXES MODIFIED}

As we have seen above, the semantics in (1) does not allow for us to define some nuances of the more specific relations between an event and a degree argument imposed by such prefixes as do-. For instance, it does not make it possible to relate the degree specifically to the final point of the event. In order for such restrictions to be represented, I propose to modify the scalar semantics for prefixes in the following way:

(30) The Scale Hypothesis (Final Version)

$$
\lambda P \lambda d \lambda x \lambda e \lambda d_{s} \cdot\left[P(x)(e) \wedge Q_{P}(d)(x)(f(e)) \wedge d R d_{s}\right]
$$

(Note that the semantics proposed for do- in (27) does constitute an instance of (30).)

Here, $P$ is the event property denoted by the verb (or by the higher verbal projection to which the prefix applies). $Q_{P}$ is a gradable property related to $P$

[14] See Rappaport Hovav (2008) for evidence that volume/extent scales are contributed by the object, rather than by the verb itself. 
in a certain way; the precise relation is underspecified in the general formula and has to be fixed for a particular prefix or a particular use of a prefix. Indeed, prefixes may differ in terms of the precise relation between $P$ and $Q_{P}$. The two properties may be identical. Alternatively, as in the case of $d 0^{-}, Q_{P}$ may stand for the property a change in which is denoted by the predicate. (For instance, if $P$ is a property of events of growing, $Q_{P}$ would be the property of being big to a degree $d$.) Finally, $f$ is a function that takes an event as its argument. The precise nature of the function is, again, determined by a prefix or by its particular use. For example, this may be a function from events to times, as is END in the semantics of do-. The application of this function allows for us to relate the degree $d$ to an event via a particular temporal stage of this event. $f$ may also be an identity function, in which case $d$ is related more directly to the event $e$.

It should be noted that if $f$ is an identity function, and it holds that $P=Q_{P}$, then (30) is reducible to (1), repeated below:

$$
\lambda P \lambda d \lambda x \lambda e \lambda d_{s} \cdot\left[P(d)(x)(e) \wedge d R d_{s}\right]
$$

Finally, turning back to the prefix pod-, its semantics under the modified approach can be represented as follows:

$$
\lambda P \lambda d \lambda x \lambda e \lambda d_{s}\left[P(x)(e) \wedge Q_{P}(d)(x)(f(e)) \wedge d<d_{s}\right]
$$

(31) is identical to (30) except for the fact that the relation between the two degrees is now fixed. The contrast between (31) and the semantics of pod- originally formulated in (3) does not affect the semantics of the sentences discussed in Section [2] in any significant way. At the same time, the pattern provided in (31) allows for us to represent the specific contribution of the different uses of pod-in a more explicit way. While the relation between the two degrees is fixed in (31), the nature of $f$ and the relation between $P$ and $Q_{P}$ is not; here, the details depend on the individual use of the prefix. For instance, pod- of approaching and podof limited change are similar to do- in that they apply to the final point of an event and to the property an increase in which is denoted by the root. The semantics of both these uses can be represented as in (32), with the difference that with pod- of approaching, $Q_{P}$ is the property of advancement along a path, whereas with podof limited change, different properties are lexicalized by different verbs, all of them being associated with a property scale.

$$
\begin{aligned}
& \lambda P \lambda d \lambda x \lambda e \lambda d_{s} \cdot\left[P(x)(e) \wedge Q_{P}(d)(x)(\operatorname{END}(e)) \wedge d<d_{s}\right] \\
& \text { where } P \text { is the event property denoted by the verbal predicate, and } Q_{P} \\
& \text { is the gradable property an increase in which is denoted by the predicate }
\end{aligned}
$$

With stative pod-, the gradable property to which the prefix applies is identical to the property denoted by the stem (i.e. $P=Q_{P}$ ). Since the resulting verb is 
stative, non-surprisingly, the compared degrees are not associated with any particular sub-interval of the time of the eventuality, but rather with the state as a whole. Finally, the standard of comparison is systematically contributed by the pragmatic context. Here, the contribution of the prefix is reduced to the following:

$$
\lambda P \lambda d \lambda x \lambda e .\left[P(d)(x)(e) \wedge d<d_{s}\right]
$$

\section{[5] THE SCALE HYPOTHESIS: DIVERSITY IN UNITY}

It can be seen that The Scale Hypothesis successfully applies to the lexical prefix pod-, the intermediate prefix do-, in addition to the superlexical po- and na-. Thus, it applies to morphemes that have different properties and do not form a natural class to the exclusion of the other verbal prefixes. As suggested above, the Scale Hypothesis seeks to capture the common semantic core shared by different prefixes, as well as by different uses of a given prefix. An additional advantage of this approach lies in its ability to predict semantic variation across prefixes in a whole range of parameters. Thus, the approach makes it possible to compare different prefixes explicitly, formulating in a clear way which properties unify them and which distinguish between them. Below, several parameters along which the prefixes are predicted to vary are briefly discussed.

(i) Most obviously, prefixes are predicted to differ in terms of the relation between two degrees that they impose (e.g. ' $<$ ' in the case of pod-, '=' for do-, ' $\geq$ ' for na-, etc.) It should be noted that the fact that a prefix may impose a relation between intervals on a scale, rather than points, makes the range of potential relations wider. For instance, two intervals may be related via the relation of inclusion. (This relation seems to be involved in the semantics of the prefix pere-, which under its most basic, spatial interpretation means 'to cross'.) Investigation of additional prefixes is needed in order to determine an exhaustive list of relations that they may encode.

(ii) Prefixes differ in the range of scales to which they apply. For some prefixes, the range of scales may be lexically determined (and, thus, in some sense analogous to selectional restrictions imposed by a predicate). In most cases, however, the range of scales can be motivated. For instance, prefixes that constitute measure functions or event delimiters can only apply to a scale if there is homomorphism between the scale and the event (cf. Součková 2004a). This restriction applies to do-, as well as po- and na-. At the same time, it does not apply to pod-, which does not have an event delimiting function under some of its uses. To illustrate, there is no homomorphism between the progress of an event and the scale to which pod- of accompanying and addition applies. 
Further, the range of scales accessible to a prefix depends on its structural position and scopal properties, as has been suggested above for the prefix pod-.

(iii) Prefixes differ in the nature of the compared degrees: they can denote relations between points on a scale (e.g. do-) or intervals (e.g. na-). Some prefixes apply only to the degree of change (na-, po-), which can be analyzed as an interval on a special, derived scale (Kennedy \& Levin 2008).

(iv) Another parameter of variation is the source of the standard of comparison. For instance, it can be provided by a linguistic expression, it may correspond to a contextually provided norm, or to the maximal point of an upper closed scale. With po- and na-, the standard of comparison can only be a contextually specified norm; with do-, on the opposite, such a standard cannot be used. Finally, with pod-, the source of the standard of comparison varies with the different uses.

(v) Finally, prefixes (as well as individual uses of a given prefix) may differ in terms of the relation that holds between the degree $d$ and the event $e$. In the case of do-, pod- of approaching and pod- of limited change, the verbs denote events of change in a certain property, and $d$ constitutes the degree to which the property holds of an argument at the endpoint of the event. In contrast, with po- and na-, $d$ corresponds to the degree of change. What unifies all these cases is that $d$ is related to the property lexicalized by the verbal stem. The case is different with pod- of limited contribution. Here, the degree $d$ measures a property that is not contributed by the stem; further, the degree is not linked to any particular part of the event. Rather, the degree measures a property which characterizes the event as a whole and along which the event can be compared to other eventualities. In order to provide a more detailed and exhaustive list of possible relations between $d$ and $e$, a larger number of prefixes has to be analyzed. I leave further investigation of this issue to future research.

Table 2 on the next page summarizes semantic properties of the four prefixes discussed in this paper, relating to the parameters listed above. The information on po- and $n a-$ is based on the discussion in Filip (2000) and Součková $(2004 a, b)$.

\section{[6] CONCLUSION}

To sum up, this paper investigated the semantics of two prefixes, pod- and do-. It has been argued that each of these morphemes, in its own way, provides evidence in favor of the scalar approach to Slavic prefixation. Under this approach, a prefix is analyzed as an element imposing a certain relation between two degrees 


\begin{tabular}{|c|c|c|c|c|c|}
\hline Prefix & Type & Relation & Scales & $\begin{array}{l}\text { The nature of } \\
\text { the degree } d\end{array}$ & $\begin{array}{l}\text { The source of } \\
\text { standard of } \\
\text { comparison }\end{array}$ \\
\hline pod- & mostly lexical & $<$ & $\begin{array}{l}\text { vertical path, } \\
\text { path,property, } \\
\text { contribution }\end{array}$ & $\begin{array}{l}\text { point } \\
\text { (typically } \\
\text { linked to the } \\
\text { endpoint of } \\
\text { the event) }\end{array}$ & $\begin{array}{l}\text { linguistic } \\
\text { expression or } \\
\text { contextually } \\
\text { provided } \\
\text { standard }\end{array}$ \\
\hline do- & intermediate & $=$ & $\begin{array}{l}\text { time, path, } \\
\text { property, } \\
\text { volume/ } \\
\text { extent }\end{array}$ & $\begin{array}{l}\text { point (always } \\
\text { linked to the } \\
\text { endpoint of } \\
\text { the event) }\end{array}$ & $\begin{array}{l}\text { linguistic } \\
\text { expression (a } \\
\text { tendency) or } \\
\text { a contextual } \\
\text { standard }\end{array}$ \\
\hline po- & superlexical & $\leq$ & $\begin{array}{l}\text { Czech: time, } \\
\text { property, } \\
\text { path, } \\
\text { ?volume/ } \\
\text { extent } \\
\text { (restricted) } \\
\text { Russian: } \\
\text { time, } \\
\text { property } \\
\text { (restricted), } \\
\text { ?volume/ } \\
\text { extent } \\
\text { (restricted) }\end{array}$ & $\begin{array}{l}\text { the degree of } \\
\text { change }\end{array}$ & $\begin{array}{l}\text { contextually } \\
\text { provided } \\
\text { expectation } \\
\text { value }\end{array}$ \\
\hline$n a-$ & superlexical & $\geq$ & $\begin{array}{l}\text { volume/extent, } \\
\text { incremental } \\
\text { experience }\end{array}$ & $\begin{array}{l}\text { the degree of } \\
\text { change }\end{array}$ & $\begin{array}{l}\text { contextually } \\
\text { provided } \\
\text { expectation } \\
\text { value }\end{array}$ \\
\hline
\end{tabular}

TABLE 2: Four Prefixes: A Summary 
on a scale - a degree associated with the event denoted by the verb and another degree, contributed either by a linguistic expression or by the context. The different uses of a given prefix are assumed to share the relation they impose but to differ in terms of the scale they apply to and, sometimes, in terms of the source and the nature of the standard of comparison. We have also considered a number of parameters along which prefixes are predicted to exhibit variation.

The approach to verbal prefixes argued for in this paper raises the following important question. The fact that prefixes of different types exhibit scalar semantics suggests that we deal with a non-accidental property that is characteristic of verbal prefixation in Slavic. Why should verbal prefixes contribute scalar meanings? There are at least two reasons for their scalar nature. First, as pointed out by Janda $(1988,328)$, most prefixes usually have a basic spatial submeaning, with their other uses corresponding to metaphorical extensions of this submeaning. Spatial meanings contributed by the more basic use can often be conceptualized as relations between two entities on a path scale (as discussed above for vertical pod-.) The metaphorical extensions can then be most naturally seen as involving the same relation between entities applied to a different type of scale.

Second, verbal prefixes typically fulfill an aspectual function, by measuring out an event or relating to its natural endpoint. It has been recently suggested that telicity and event delimitation can be analyzed in scalar terms, and attributed to a bounded degree of change (Kennedy \& Levin 2002, 2008; Součková 2004a) or to the notion of maximalization (Filip 2008). If this approach to telicity is correct, then the scalar semantics of prefixes is non-surprising.

\section{REFERENCES}

Babko-Malaya, Olga. 1999. Zero Morphology: A Study of Aspect, Argument Structure and Case: The State University of New Jersey, Doctoral dissertation.

Braginsky, Pavel. 2008. The Semantics of the Prefix ZA- in Russian: Bar-Ilan University, Doctoral dissertation.

Dowty, David R. 1979. Word and Meaning in Montague Grammar. Dordrecht: Reidel Publishing.

Filip, H. \& S. Rothstein. 2006. Some title. In Someone (ed.), $k f d, 22-34$.

Filip, Hana. 2000. The Quantization Puzzle. In C. Tenny \& J. Pustejovsky (eds.), Events as Grammatical Objects, 3-60. Standford: CSLI Publications.

Filip, Hana. 2005. Measures and Indefinites. In G. N. Carlson \& J. F. Palletier (eds.), References and Quantification: The Partee Effect, 229-288. Standford: CSLI Publications. 
Filip, Hana. 2008. Events and Maximalization: The case of telicity and perfectivity. In Susan Rothstein (ed.), Theoretical and Crosslinguistic Approaches to the Semantics of Aspect, 217-256. John Benjamins.

Greenberg, Yael. 2009. Additivity in the Domain of Eventualities. In Proceedings of the 10th Symposium on Logic and Language., Budapest, Hungary.

Hay, J., C. Kennedy \& B. Levin. 1999. Scale structure underlies telicity in 'degree achievements'. In T. Matthews \& D. Strolovitch (eds.), Semantics and Linguistic Theory, vol. 9, 127-144. Ithaca, NY: CLC Publications.

Janda, Laura. 1988. The Mapping of Elements of Cognitive Space onto Grammatical Relations: An Example from Russian Verbal Prefixation. In B. Rudzka-Ostyn (ed.), Topics in Cognitive Linguistics, 327-343. Amsterdam: John Benjamins.

Kennedy, C. \& B. Levin. 2002. Telicity Corresponds to Degree of Change. Unpublished ms., Northwestern University and Standford University.

Kennedy, C. \& B. Levin. 2008. Measure of Change: The Adjectival Core of Degree Achievements. In L. McNally \& C. Kennedy (eds.), Adjectives and Adverbs: Syntax, Semantics and Discourse, 156-183. Oxford: Oxford University Press.

Kennedy, C. \& L. McNally. 2005. Scale structure, degree modification, and the semantics of gradable predicates. Language 81(2). 345-381.

Landman, F. 2008. On the differences between the tense-perspective-aspect systems of English and Dutch. In S. Rothstein (ed.), Theoretical and Crosslinguistic Approaches to the Semantics of Aspect, 107-167. Amsterdam: John Benjamins.

Levinson, S.C. 2001. Space: Linguistic expression. In N.J. Smelser \& P. Baltes (eds.), International Encyclopedia of Social and Behavioral Sciences, vol. 22, 14749-14752. Oxford: Pergamon.

Paillard, D. 1997. Formal'noje predstavlenije pristavki ot-. In M.A. Krongauz \& D. Paillard (eds.), Glagol'naja prefixacija v russkom jazyke: sbornik statej, Moscow: Russkije slovari.

Piñón, C. 2008. Aspectual composition with degrees. In McNally L. \& C. Kennedy (eds.), Adjectives and Adverbs: Syntax, Semantics, and Discourse, 183-219. Oxford University Press. http://pinon.sdf-eu.org/covers/acd.html.

Plungyan, V.A. 2001. Pristavka pod- v russkom jazyke: K opisaniju semantičeskoj seti. Moskovskij lingvističeskij žurnal 5. 95-124.

Ramchand, G. 2004. Time and the event: The semantics of Russian prefixes. Nordlyd 32(2). 323-361. 
Rappaport Hovav, Malka. 2008. Lexicalized Meaning and the Internal Structure of Events. In S. Rothstein (ed.), Theoretical and Crosslinguistic Approaches to the Semantics of Aspect, Amsterdam: John Benjamins.

Rappaport Hovav, Malka. 2009. Scalar Roots and their Results. Handout of talk, Workshop on Roots: Word Formation from the Perspective of 'Core Lexical Elements', Universität Stuttgart.

Romanova, Eugenia. 2004. Superlexical vs. Lexical Prefixes. Norlyd 32(2). 255-278.

Rothstein, S. 2008. Two Puzzles for a Theory of Lexical Aspect: The Case of Semelfactives and Degree Adverbials. In J. Dölling, T. Heyde-Zybatowand \& M. Shaefer (eds.), Event Structures in Linguistic Form and Interpretation, Berlin: Mouton De Gruyter.

Součková, Kateřina. 2004a. Measure Prefixes in Czech: Cumulative na- and Delimitative po-. University of Tromso. Unpublished M.A. thesis.

Součková, Kateřina. 2004b. There's only one po-. Nordlyd 32(2). 403-419.

Svenonius, Peter. 2004. Slavic Prefixes inside and outside VP. Nordlyd 32(2). 205-253.

Tatevosov, Sergei. 2008. Intermediate Prefixes in Russian. In A. Antonenko et al. (eds.), Annual Workshop on Formal Approaches to Slavic Linguistics: The Stony Boook Meeting, 423-445. Ann Arbor: Michigan Slavic Publications.

AUTHOR CONTACT INFORMATION

Olga Kagan

Ben-Gurion University of the Negev

olga@sharat.co.il 